\title{
A Cost Effective Method to Fabricate an Interim Finger Prosthesis
}

\author{
Anand, Faris Mohammed Shafi* and Nishna Pradeep
}

Department of Prosthodontics, Kannur Dental College, Kannur, Kerala, India

\begin{abstract}
Aim of study: Sudden loss of finger causes marked psychological trauma to the patient besides varying degrees of functional disability depending upon the extent of trauma and disfigurement. The main objective of prosthesis in this case was to provide a cost effective, temporary, esthetic prosthesis to mask the disfigurement caused by three missing fingers on the right hand till a definitive prosthesis can be fabricated.
\end{abstract}

Case report: This report describes a simple technique for fabrication of a temporary acrylic finger prosthesis for a patient using a novel technique with an alginate template and incremental layering of acrylic resin.

Conclusion: The proposed technique is simple and cost effective way to make a satisfactory temporary acrylic prosthesis.

Keywords: Temporary finger prosthesis; Acrylic finger prosthesis

\section{Introduction}

Finger or partial finger amputations are a common occupational hazard seen in laborers handling heavy duty machinery [1]. Sudden loss of finger causes marked psychological trauma to the patient besides varying degrees of functional disability depending upon the extent of trauma and disfigurement [2]. A precisely fitting prosthesis can improve function by restoring normal length, protecting the stump, maintaining sensitivity through the thin layer of the prosthesis and transmitting pressure and position sense for activities such as writing or typing [3,4]. Such prosthesis serves to rehabilitate the patient, and helps to boost the morale of the patient following a traumatic accident [5].

Currently, many injuries and traumatic amputations of fingers can be rehabilitated by microsurgery through reimplantation [6]. For some, reconstructive surgery cannot be performed due to the severity of the injury, technical difficulties, financial and psychological issues, or due to surgical complications and failure [6]. At this juncture a cosmetic replacement of the lost finger helps the patient to overcome the psychological trauma caused by the loss and enables him to continue social interactions with renewed confidence [5]. The major role in rehabilitating the patient is thus played by the maxillofacial prosthodontist. Studies proved that when surgical reconstruction of lost finger is contraindicated, unsuccessful or unavailable, prosthesis can provide and offer great psychological help [7]. Prosthetic replacement of fingers can be satisfactory in patients who have at least $1.5 \mathrm{~cm}$ of Residual stump [7]. The osseointegrated digital prosthesis is an alternate technique for patients with short stump on which a standard digital prosthesis is attached securely by means of an osseointegrated implant placed on intramedullary canal of residual bone of the amputated digit [8]. The purpose of this report is to describe a simple technique for fabrication of acrylic finger prosthesis for a patient following an industrial accident at a plywood factory. The main objective of prosthesis in this case was to provide a cost effective, temporary, esthetic prosthesis to mask the disfigurement caused by three missing fingers on the right hand till a definitive prosthesis can be fabricated.

\section{Case Report}

A 27 year old male reported to the department of prosthodontics for replacement of his multiple fingers lost in an industrial accident at his work place 4 months back. History revealed that his right hand got entangled in a chain saw and his middle, ring and little finger got severed at the level of proximal interpharyngeal joint. The patient had undergone surgery for the same and he was referred to prosthodontics department for cosmetic replacement. At the time of patents first visit, the healing was incomplete (Figure 1) and his morale was very low.

\section{Treatment procedure}

Temporary acrylic finger prosthesis was planned for all the three amputated fingers. Patient was briefed about the advantages and disadvantages of the procedure and informed consent of the patient was obtained. The economic status of the patient ruled out the possibility of rehabilitating him with silicon prosthesis.

\section{Impression making and model preparation}

Patient's right hand was lubricated with petroleum jelly so as to prevent the impression material from adhering to the skin and eventual distortion of the impression. Alginate (Algitex, DPI India) was mixed and applied first in a thin layer covering the entire surface and thereby

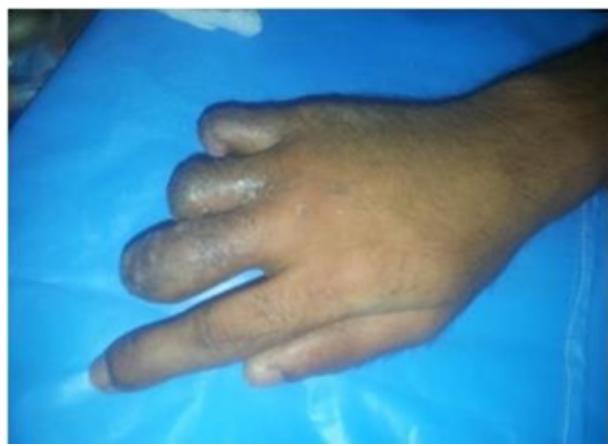

Figure 1: Amputated fingers with incomplete healing.

${ }^{*}$ Corresponding author: Faris Mohammed Shafi, Assistant professor, Kannu Dental College, Department Of Prosthodontics, Anjarakandy Integrated Campus Kannur, Kerala, India 670612, Tel: +919895198528; E-mail: dr.faris@outlook.com

Received April 09, 2015; Accepted July 16, 2015; Published July 25, 2015

Citation: Anand, Shafi FM, Pradeep N (2015) A Cost Effective Method to Fabricate an Interim Finger Prosthesis. Dentistry 5: 323. doi:10.4172/2161-1122.1000323

Copyright: (c) 2015 Anand, et al. This is an open-access article distributed under the terms of the Creative Commons Attribution License, which permits unrestricted use, distribution, and reproduction in any medium, provided the original author and source are credited. 
avoiding any air bubble entrapment and then sufficient bulk of alginate was applied and a gauze covering was placed on the partially set alginate to act as retention for the plaster of Paris layer to be applied after the impression material was set.

Type III dental stone (Gold stone, Asian chemicals, India) was poured into the impression, allowed to set and the stone model was obtained (Figure 2).

\section{Stump preparation and wax pattern fabrication}

A wax up of the fingers was fabricated after slightly sand papering the finger stumps of the model for better fit of the prosthesis. Characterization was done to incorporate fingerprints, nails and other features to mimic the texture of the skin. Try in of the wax mockup was done and necessary modifications were made (Figure 3).

\section{Alginate impression of wax pattern and acrylic shell fabrication on the alginate template}

Two separate alginate impressions of the wax pattern were made. One on the dorsal side and the other on the palmar side (Figures 4 and 5) of the wax finger pattern. The skin and the nail part of the dorsal side of the prosthesis were fabricated together as an acrylic shell by incremental addition of acrylic. Self-cure acrylic resin (clear shade and pink) was mixed in increments for the nail part and oil color pigments mainly burnt sienna, white and yellow was used to the shade skin part according to the complexion of the patient. The mix was then incorporated into the mould in a thin layer (Figure 6). Subsequent layers of acrylic resin were added to match the skin and the nail color. The shade was verified by keeping the cured acrylic shell on the patients stump and further adjustments in color were made.

The stria on the skin overlying the interpharyngeal joints was defined by thin strokes of black and brown color using a fine paint brush. After the acrylic shells for the dorsal side was fabricated in this manner the palmar side was completed in a similar manner. The oil pigments used for forming the acrylic shell of the palmar aspect of the prosthesis were mainly pink and yellow. The acrylic shells were tried in the patient and fit and shade were verified. The dorsal and palmar side acrylic shells were then joined together with self-cure acrylic resin. Even though initially a ring was planned for additional retention, the bulk of the stump at the level of amputation created a huge undercut, thereby interfering with its placement and removal. The borders of the prosthesis were masked with hair to mimic the same on the contralateral fingers.

\section{Insertion of the final prosthesis and maintenance instructions}

Patient was advised to remove the prosthesis at night. The prosthesis

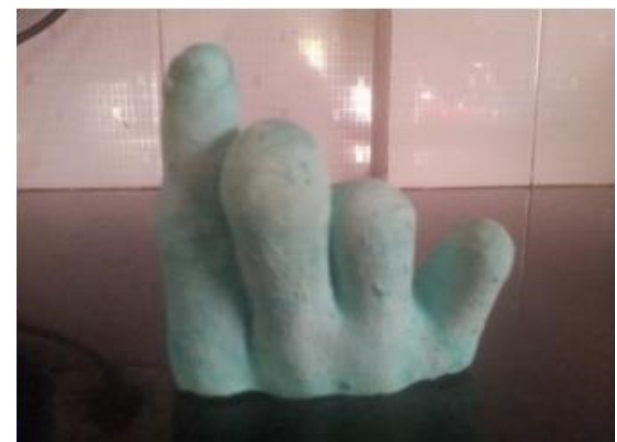

Figure 2: Dental stone model of the amputated hand

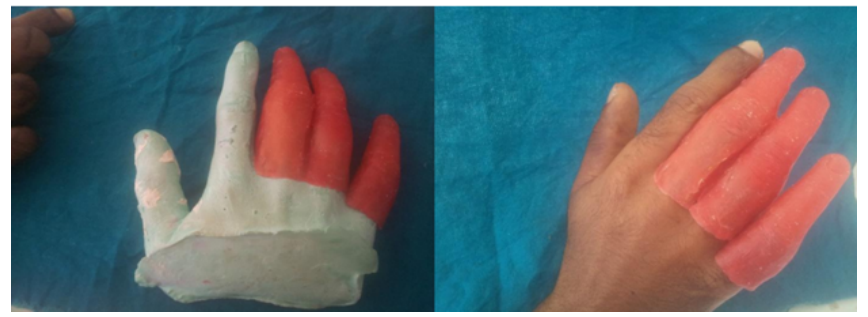

Figure 3: Wax mock up and its trial on the patient.

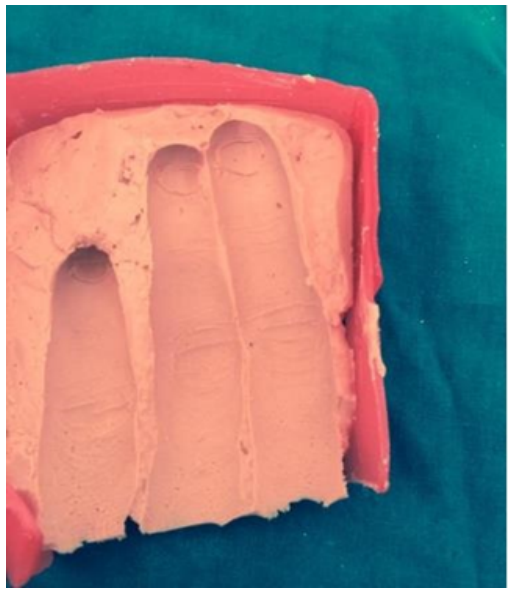

Figure 4: Alginate template.

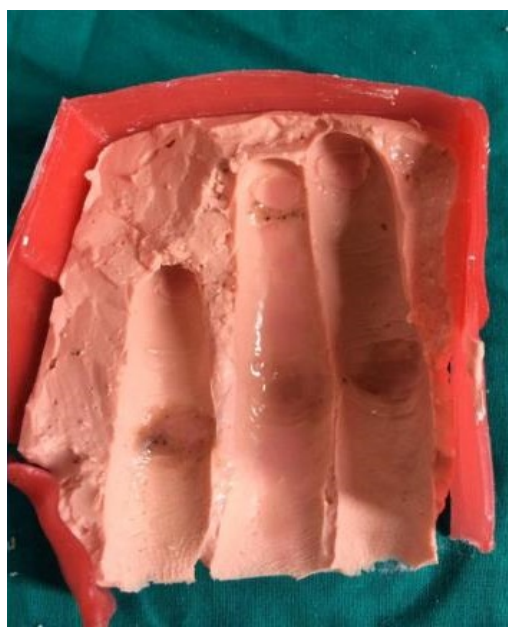

Figure 5: Alginate template after application of resin and stains.

is to be cleaned gently with soap and water. The finger stump should be massaged to increase the circulation.

\section{Discussion}

Traumatically amputated digits can be preserved by micro surgical reimplantation or osseointegrated digital prosthesis [9]. In this case surgical reimplantation was not possible as the finger was crushed and osseointegrated implants were ruled out due to economic reasons. As the amputated stumps were too thick, a second corrective surgical 


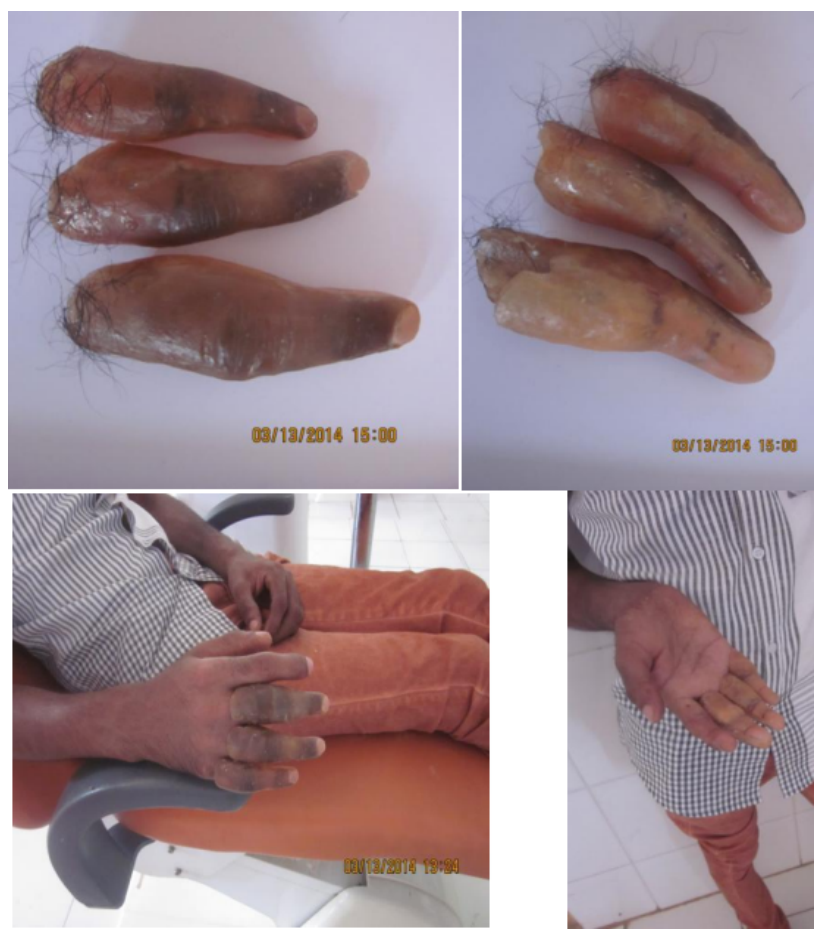

Figure 6: Completed finger prosthesis.

procedure was planned at a later stage to improve esthetics of the final prosthesis. In the interim stage, temporary cost effective acrylic resin prosthesis was planned in order to boost the morale of the patient and to enable him to continue normal social interactions. The acrylic temporary prosthesis is rigid and can be fabricated in very thin sections. The acrylic shell incorporated both nail and skin part together, this again made the fabrication easier and risk of nail separating from the prosthesis was nullified. Building up of the prosthesis incrementally enabled to obtain the different color saturation at the different regions of the skin overlying the finger satisfactorily. It can also be modified to adapt the skin to make it more esthetic. The retention of the prosthesis was done by a $0.5 \mathrm{~mm}$ of circumferential reduction of the stump diameter. Pereira et al. [10] fabricated 136 digital prostheses for 90 patients. Retention and fit of these prostheses were achieved through modification of the inner circumference of the mould.

\section{Conclusion}

A convenient and affordable method of temporary prosthetic rehabilitation of amputated fingers has been presented. The custom made acrylic finger prosthesis is esthetically acceptable, easy and cost effective to fabricate. Patient was highly satisfied with this prosthesis in terms of retention and esthetics. The morale of the patient was also boosted to a great extent.

\section{References}

1. Nag PK, Patel VG (1998) Work accidents among shift workers in industry. Int J Ind Ergonom 21: 275-281.

2. Singhal S, Chand P, Singh SV, Tripathi S (2011) Case report: modifications to simplify fabrication of finger prosthesis: a case series. J Prosthet Orthot 23: 30-33.

3. Pillet J (1983) Esthetic hand prostheses. J Hand Surg Am 8: 778-781.

4. Beasley RW, de Beze GM (1990) Prosthetic substitution for fingernails. Hand Clin 6: 105-110.

5. Kaira LS, Dabral E (2012) Glove type silicone finger prosthesis-a case report. Ind J Dent Sciences 4: 40-41.

6. Aydin C, Karakoca S, Yilmaz H (2007) Implant-retained digital prostheses with custom-designed attachments: a clinical report. J Prosthet Dent 97: 191-195.

7. Pilley MJ, Quinton DN (1999) Digital prostheses for single finger amputations. $\mathrm{J}$ Hand Surg Br 24: 539-541.

8. Lundborg G, Brånemark PI, Rosén B (1996) Osseointegrated thumb prostheses: a concept for fixation of digit prosthetic devices. J Hand Surg Am 21: $216-221$.

9. Michael JW, Buckner H (1994) Options for finger prosthesis. J Prosthet Orthot 6: 10-14.

10. Pereira BP, Kour AK, Leow EL, Pho RW (1996) Benefits and use of digital prostheses. J Hand Surg Am 21: 222-228. 